\title{
Spectrophotometric Determination of Niobium with Hydrogen Peroxide and 2-(5-Bromo-2-pyridylazo)-5-diethylaminophenol in Steel and Apatite after Its Extractive Separation as $\alpha$-Benzoin Oxamate
}

\author{
Maciej JAROSZ and Sławomir OszwaEDowSKI \\ Department of Analytical Chemistry, Technical University, \\ ul.Noakowskiego 3, 00-664 Warsaw, Poland
}

\begin{abstract}
A sensitive method for the spectrophotometric determination of niobium(V) based on the formation of its complex with 2-(5-bromo-2-pyridylazo)-5-diethylaminophenol in the presence of hydrogen peroxide has been developed. The molar absorptivity at $591 \mathrm{~nm}$ is $7.43 \times 10^{4} 1 \mathrm{~mol}^{-1} \mathrm{~cm}^{-1}$ at pH $4.0 \pm 1.0$. This method becomes selective for niobium(V) after a preliminary extraction of its complex with $\alpha$-benzoin oxime from 5-9 M hydrochloric acid, thus permitting the determination of traces of niobium in the presence of a large amount of other ions. It has been applied to the determination of niobium in materials of certified $\mathrm{Nb}$ content: steel and apatite samples.
\end{abstract}

Keywords Spectrophotometry, 2-(5-bromo-2-pyridylazo)-5-diethylaminophenol, extraction, $\alpha$-benzoin oxime, niobium determination, steel, apatite

Most of the known spectrophotometric methods used for niobium(V) determination are not very sensitive. The molar absorptivities of the methods frequently used, with thiocyanate or with Bromopyrogallol Red are $3.5 \times 10^{4}$ or $4.75 \times 10^{4} 1 \mathrm{~mol}^{-1} \mathrm{~cm}^{-1}$, respectively. ${ }^{1}$ Even such efficient reagents as thiazolylazo or pyridylazo derivatives do not form sensitive systems with nio$\operatorname{bium}(\mathrm{V})$; the molar absorptivities of methods based on these systems exceptionally. ${ }^{2}$ Moreover, the spectrophotometric methods used for niobium determination generally have disadvantages regarding selectivity as well as a rather long time required for full color development (about $1 \mathrm{~h}$ ). The other instrumental techniques also do not offer a very sensitive determination of niobium. For example, in flame AAS the characteristic concentration is about $40 \mathrm{mgNb} / \mathrm{l}$, and only when a nitrous oxide/acetylene flame is used. ${ }^{3}$

Because most of the spectrophotometric methods used for $\mathrm{Nb}$ determination are not selective, preliminary masking of the matrix components or the separation of niobium is usually necessary. The interfering ions most often mask with EDTA, cyanide, oxalate, or tartrate. ${ }^{1}$ Of the separation methods proposed for niobium(V), solvent extraction seems to be most useful. Despite the apparent versatility of the extraction procedures, they are suitable only for the analysis of definite materials. Even the highly selective extraction of a niobium(V) complex with $N$-benzoyl- $N$-phenylhydroxylamine (BPHA) from a hydrochloric acid media does not ensure the effective separation of $\mathrm{Nb}$ traces, even from so small an amount of $\mathrm{Zr}$ or $\mathrm{Ti}$ as $10 \mu \mathrm{g} .{ }^{4,5}$
The present paper concerns a simple and sensitive spectrophotometric method for determining microgram amounts of niobium, based on its complex with 2-(5bromo-2-pyridylazo)-5-diethylaminophenol (5-BrPADAP) in the presence of hydrogen peroxide. After the extractive separation of $\mathrm{Nb}(\mathrm{V})$ as $\alpha$-benzoin oxamate, niobium was determined in steel and apatite samples.

\section{Experimental}

\section{Apparatus}

A VSU-2P spectrophotometer was used to perform absorbance measurements and a Specord UV-VIS spectrophotometer for recording the spectra. Glass cells of 10-mm path length were used. An ELPO N-517 $\mathrm{pH}$ meter was used to measure the $\mathrm{pH}$.

\section{Reagents}

All of the reagents were of analytical-reagent grade.

Niobium(V) stock solution $(1 \mathrm{mg} / \mathrm{ml})$ : Dissolve $0.1430 \mathrm{~g}$ of niobium pentoxide in $1 \mathrm{ml}$ of concentrated sulfuric acid containing $0.5 \mathrm{~g}$ of ammonium sulfate under gentle heating in a platinum crucible. Dilute the obtained solution to $100 \mathrm{ml}$ with concentrated hydrochloric acid.

2-(5-Bromo-2-pyridylazo)-5-diethylaminophenol: $0.075 \%$ solution in methanol.

Hydrogen peroxide solution: $1.5 \%$.

$\alpha$-Benzoin oxime: $6 \%$ solution in methanol. 
Zephiramine (Zeph), Triton X-100, sodium dodecyl sulfate (SDS) solutions: $0.2 \mathrm{M}$.

Apatite: CTA-AC-1 (Institute of Nuclear Chemistry and Technology, Warsaw, Poland).

Steel samples (ASMW, IMŹ): Institute of Ferrous Metallurgy, Gliwice, Poland.

\section{General procedure}

To an appropriate volume of a sample solution containing up to $20 \mu \mathrm{g}$ of $\mathrm{Nb}(\mathrm{V})$, add $2 \mathrm{ml}$ of the hydrogen peroxide solution, $0.5 \mathrm{ml}$ of the 5-Br-PADAP solution, and $5 \mathrm{ml}$ of methanol. Adjust the $\mathrm{pH}$ to $4.0 \pm 1.0$ by means of a dilute ammonia solution. Transfer the solution into a $25-\mathrm{ml}$ volumetric flask, fill with water to the mark, and measure the absorbance at $591 \mathrm{~nm}$ after 15 min against a reagent blank.

\section{Determination of niobium in steel}

After placing a weighed amount of steel into a $50-\mathrm{ml}$ beaker, add $10 \mathrm{ml}$ of $6 \mathrm{M}$ sulfuric acid and $1.5 \mathrm{ml}$ of concentrated phosphoric acid. Heat gently, and then carefully add $1.5 \mathrm{ml}$ of concentrated nitric acid. After complete dissolution of the sample, evaporate the solution almost to dryness. Dissolve the cooled residue in concentrated hydrochloric acid, transfer the solution into a volumetric flask and fill to the mark with concentrated hydrochloric acid (the weighed amount of the sample and size of the used volumetric flask depend on the niobium content in the analyzed steel; they should ensure a final niobium concentration of about $1 \mu \mathrm{g} / \mathrm{ml}$ ). Pipet $10 \mathrm{ml}$ of the solution into a $50-\mathrm{ml}$ separatory funnel, add $10 \mathrm{ml}$ of $3.0 \mathrm{M}$ hydrochloric acid, mix, add $0.3 \mathrm{ml} \alpha$-benzoin oxime solution and allow the funnel to stand for $3 \mathrm{~min}$. Shake the water phase with two successive 10-ml portions of chloroform for $3 \mathrm{~min}$. After washing the combined chloroform extracts with $10 \mathrm{ml}$ of $5 \mathrm{M}$ hydrochloric acid, transfer into a $25-\mathrm{ml}$ beaker and evaporate to dryness. Mineralize the residue with $1 \mathrm{ml}$ of concentrated sulfuric acid and $2-3$ drops of concentrated nitric acid. Evaporate the solution almost to dryness, dissolve the residue in $10 \mathrm{ml}$ of water and determine the niobium according to the General procedure.

\section{Determination of niobium in apatite}

Place a 0.25 -g sample of apatite into a 50-ml Teflon beaker. Add $5 \mathrm{ml}$ of concentrated hydrochloric acid and gently heat for $15 \mathrm{~min}$. Dilute with $2 \mathrm{ml}$ of water and filter through Filtrak 388 quantitative filter paper (with soft and wide pores) to remove any insoluble parts. After combusting the filter paper in a platinum crucible, add to the residue $1 \mathrm{ml}$ of concentrated perchloric acid and $1 \mathrm{ml}$ of concentrated hydrofluoric acid. Evaporate the solution to near dryness in order to remove any excess hydrofluoric acid. Transfer a solution (about $0.5 \mathrm{ml}$ ) free of fluoride into a beaker containing the previously obtained filtrate. Evaporate the combined liquids almost to dryness. Dissolve the residue in $10 \mathrm{ml}$ of concentrated hydrochloric acid, and then transfer the solution into a separatory funnel. Carry out an extraction and the determination of $\mathrm{Nb}(\mathrm{V})$ according to "Determination of niobium in steel" and the General procedure.

\section{Results and Discussion}

\section{Spectrophotometric determination of niobium}

In preliminary experiments it was found that niobium(V) did not form a colored compound with 5-BrPADAP alone. However, the presence of such ligands as peroxide or tartrate (oxalate is inactive) led to the formation of colored species. Both systems were examined in order to select the best one as a basis to develop a sensitive method for the determination of niobium. In each experiment the reagent concentrations were kept constant: $c_{\mathrm{Nb}}=5.5 \times 10^{-6} \mathrm{M}, c_{5-\mathrm{Br} \text {-PADAP }}=$ $4.5 \times 10^{-5} \mathrm{M}$, and $c_{\mathrm{MeOH}}=20 \%(\mathrm{v} / \mathrm{v})$. Under such conditions complexes were formed at $\mathrm{pH}$ ranges: $4.0 \pm 0.5$ for the tartrate system and $4.0 \pm 1.0$ for the peroxide system (Fig. 1). The maximum absorbances were measured for a ligand concentration above $2 \times 10^{-2} \mathrm{M}$ (peroxide) and $3 \times 10^{-2} \mathrm{M}$ (tartrate). Because of the significantly lower absorbances obtained for the tartrate system (at an absorption maximum of $603 \mathrm{~nm}$ ) than for peroxide (at $591 \mathrm{~nm}$ ), the latter was chosen.

Since both the reagent and the niobium complex are insoluble in water, it is necessary to add a solubilizing agent. Very popular surfactants and methanol were examined as such agent. As shown in Fig. 2, sodium dodecyl sulfate (SDS) (anionic surfactant) is useless. Higher absorbances were obtained when Triton X-100 (nonionic) or Zephiramine (cationic) were added. However, methanol gave the best results at concentrations of $10-35 \%(\mathrm{v} / \mathrm{v})$; this reagent was thus adopted.

The selected system ( $\mathrm{Nb}(\mathrm{V})-\mathrm{H}_{2} \mathrm{O}_{2}-5$-Br-PADAP) was examined in detail. It was established that the maxi-

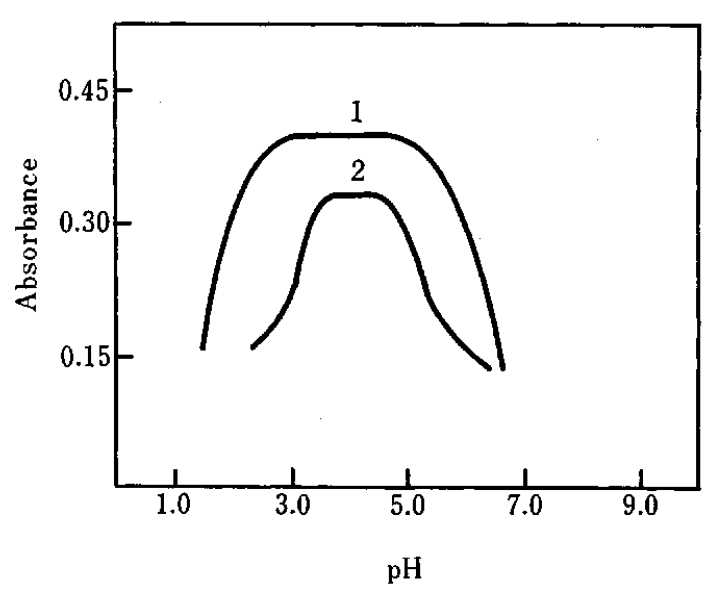

Fig. 1 Effect of the $\mathrm{pH}$ on the absorbances of niobium complexes with 5-Br-PADAP. $\quad c_{\mathrm{Nb}}=5.4 \times 10^{-6} \mathrm{M}, c_{5-\mathrm{Br}-\mathrm{PADAP}}=4.3 \times$ $10^{-5} \mathrm{M}, c_{\mathrm{MeOH}}=20 \%$; line 1: $\mathrm{Nb}-\mathrm{H}_{2} \mathrm{O}_{2}-5-\mathrm{Br}-\mathrm{PADAP}, \lambda=591$ $\mathrm{nm}$; line 2: Nb-tartrate-5-Br-PADAP; $\lambda=603 \mathrm{~nm}$. 


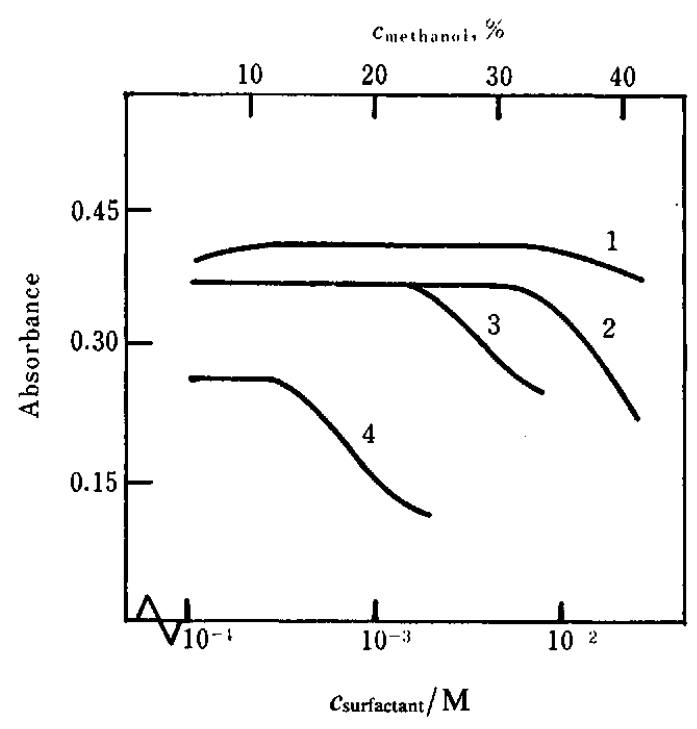

Fig. 2 Effect of a surfactant or methanol on the absorbances of a niobium complex with 5-Br-PADAP in the presence of hydrogen peroxide. $c_{\mathrm{Nb}}=5.4 \times 10^{-6} \mathrm{M}, c_{5 \text {-Br-PADAP }}=4.3 \times 10^{-5}$ $\mathrm{M}, c_{\mathrm{MeOH}}=20 \%, c_{\mathrm{H} 2 \mathrm{O} 2}=4.0 \times 10^{-2} \mathrm{M}, \mathrm{pH}=3.3$, line 1 : methanol; line 2: Triton X-100; line 3: Zephiramine; line 4: sodium dodecyl sulfate (SDS).

mum absorbances were obtained when the chromogenic reagent was present in concentrations of $2.5 \times 10^{-5}$ $1.3 \times 10^{-4} \mathrm{M}$. The color development time was $15 \mathrm{~min}$, and the absorbance was stable for at least $1 \mathrm{~h}$.

The calibration curve prepared under optimum conditions obeys Beer's law up to $0.8 \mu \mathrm{gNb}(\mathrm{V}) / \mathrm{ml}$, and the molar absorptivity is $7.43 \times 10^{4} 1 \mathrm{~mol}^{-1} \mathrm{~cm}^{-1}$ at $591 \mathrm{~nm}$. At the maximum absorption of the complex the blank value is inconsiderable (about 0.05 ).

The molar ratio $\mathrm{Nb}: 5-\mathrm{Br}-\mathrm{PADAP}$ in the complex evaluated by Job's method is $1: 1$. The simple approaches usually used to establish complex compositions were unsuitable for evaluating the molar ratio $\mathrm{Nb}(\mathrm{V}): \mathrm{H}_{2} \mathrm{O}_{2}$ due to the large excess of peroxide necessary to form the complex.

Unfortunately, the developed method, which is really sensitive, is not selective for niobium (e.g. seriously interfering ions include Ti(IV), $\mathrm{V}(\mathrm{V}), \mathrm{Zr}(\mathrm{VI}), \mathrm{Mo}(\mathrm{VI})$ and Hf(IV)-among those which form complexes with hydrogen peroxide, and a number of others which react with 5-Br-PADAP6). The interference of other cations was therefore studied in a full procedure which included separation (see below). The influence of the ionic strength of the solution on niobium complex formation was evaluated. The sodium nitrate, chloride or sulfate present in solution in concentrations of up to $0.1 \mathrm{M}$ did not affect the absorbance. Increasing the concentration of inert salt to $0.15 \mathrm{M}$ resulted in about a $7 \%$ decrease in the absorbances.

It was also evaluated that thiocyanate in 300 -fold molar excess with respect to $\mathrm{Nb}(\mathrm{V})$, fluoride (100-fold) and EDTA (10-fold) did not influence the formation of the $\mathrm{Nb}(\mathrm{V})-\mathrm{H}_{2} \mathrm{O}_{2}-5-\mathrm{Br}-\mathrm{PADAP}$ complex.

\section{Extractive separation of niobium}

The determination of niobium with $\mathrm{H}_{2} \mathrm{O}_{2}$ and 5-BrPADAP in real materials requires a preliminary separation. A very promising method, owing to its selectivity, seems to be extraction of the $\mathrm{Nb}(\mathrm{V})$ complex with $\alpha$-benzoin oxime; ${ }^{7}$ the niobium complex could be extracted with chloroform from an aqueous media containing hydrochloric acid in concentrations of 1 $11 \mathrm{M}$ in the absence of fluoride, oxalate and tartrate.

The original procedure ${ }^{7}$ promises a complete separation of $10 \mu \mathrm{g}$ of niobium from a $5 \mathrm{M}$ hydrochloric acid medium with one $10-\mathrm{ml}$ portion of a $0.2 \%$ chloroform solution of $\alpha$-benzoin oxime. Our experiments proved that under such conditions extraction with three portions of the reagent solution gave only about a $30 \%$ recovery of niobium. However, a quantitative separation of niobium could be obtained when its solution in concentrated hydrochloric acid was diluted with $3 \mathrm{M}$ hydrochloric acid (to give final concentrations of 5 $9 \mathrm{M}$ ) just before the addition of $\alpha$-benzoin oxime and extraction with chloroform. The modified procedure probably prevents the hydrolysis of niobium(V). Moreover, extraction from solutions of a higher hydrofluoric acid concentration (above $5 \mathrm{M}$ ) allows the separation of $\mathrm{Nb}(\mathrm{V})$ from molybdenum. The earlier proposed back-extraction of niobium with concentrated hydrochloric acid ${ }^{7}$ was unsuitable for the following spectrophotometric determination. A high chloride concentration inhibited color reaction with $5-\mathrm{Br}$ PADAP, and evaporation of any excess hydrochloric acid was impossible, due to the precipitation of a large amount of co-extracted $\alpha$-benzoin oxime. The combined chloroform extracts were therefore evaporated, and the residue was mineralized with $1 \mathrm{ml}$ of concentrated sulfuric acid and 2-3 drops of concentrated nitric acid. Such a procedure gave about a $97 \%$ recovery of niobium (mineralization with a mixture of nitric and perchloric acid gave a niobium recovery of $80 \%$ ).

In order to check the accuracy and precision of the developed procedure (included extraction step, evaporation of chloroform, mineralization of a residue with sulfuric and nitric acids and determination of $\mathrm{Nb}(\mathrm{V})$ with hydrogen peroxide and 5-Br-PADAP) niobium was determined in synthetic mixtures containing the following ions (100 $\mu \mathrm{g}$ each): Ti(IV), V(V), $\mathrm{Cr}$ (III), $\mathrm{Mn}(\mathrm{II}), \mathrm{Fe}$ (III), Co(II), Ni(II), Cu(II), Zn(II), Ga(III), Zr(IV), Mo(VI), Pd(II), Cd(II), Sn(IV), Sb(V), Ta(V), W(VI), Pt(IV), Tl(III), Pb(II) and Bi(III). The obtained data are shown in Table 1.

\section{Preliminary preparation of apatite and steel samples for the determination of niobium}

The previously reported methods for the dissolution of some geological materials ${ }^{5,8}$ are not suitable for apatite containing large amount of calcium, phosphate, fluoride or silicon. The use of hydrofluoric acid results in the formation of insoluble calcium fluoride. The removal of fluoride from such an obtained mixture is impossible, 
Table 1 Precision data for the determination of niobium in synthetic mixtures containing the following ions $(100 \mu \mathrm{g}$ each): Ti(IV), V(V), Cr(III), Mn(II), Fe(III), Co(II), $\mathrm{Ni}(\mathrm{II}), \mathrm{Cu}(\mathrm{II}), \mathrm{Zn}(\mathrm{II}), \mathrm{Ga}(\mathrm{III}), \mathrm{Zr}(\mathrm{IV}), \mathrm{Mo}(\mathrm{VI}), \mathrm{Pd}(\mathrm{II})$, Cd(II), Sn(IV), Sb(V), Ta(V), W(VI), Pt(IV), Tl(III), $\mathrm{Pb}(\mathrm{II})$ and $\mathrm{Bi}(\mathrm{III})$

\begin{tabular}{cccc}
\hline \multicolumn{2}{c}{ Niobium $/ \mu \mathrm{g}$} & $\begin{array}{c}\text { RSD, } \% \\
(n=7)\end{array}$ & Confidence limits $^{\mathrm{a}}$ \\
\cline { 1 - 2 } Added & Found & & \\
\hline 2.5 & 2.6 & 5.3 & $2.6 \pm 0.2$ \\
10.0 & 9.9 & 2.6 & $9.9 \pm 0.3$ \\
20.0 & 19.6 & 2.1 & $19.6 \pm 0.4$ \\
\hline
\end{tabular}

a. Probability level 0.95 .

Table 2 Determination of niobium in CTA-AC-1 certified apatite (niobium content, $\left.(4.32 \pm 1.24) \times 10^{-3} \%\right)$

\begin{tabular}{|c|c|c|c|c|}
\hline \multirow{2}{*}{ Sample/g } & \multicolumn{2}{|c|}{ Niobium $/ \mu \mathrm{g}(\%)$} & \multirow{2}{*}{$\begin{array}{c}\mathrm{RSD}, \% \\
(n=7)\end{array}$} & \multirow{2}{*}{$\begin{array}{c}\text { Confidence } \\
\text { limit }^{\mathrm{a}}\end{array}$} \\
\hline & Added & Found & & \\
\hline 0.25 & - & $\begin{array}{c}8.9 \\
\left(3.56 \times 10^{-3}\right)\end{array}$ & 5.6 & $\begin{array}{c}(3.56 \pm 0.18) \\
\times 10^{-3}\end{array}$ \\
\hline 0.25 & 6.0 & 13.6 & & \\
\hline
\end{tabular}

a. Probability level 0.95 .

even by evaporation with perchloric, sulfuric or phosphoric acid; the presence of these ions strongly interferes with the extraction of niobium with $\alpha$-benzoin oxime.

In this work apatite was dissolved in two successive steps. First, the sample was treated with concentrated hydrochloric acid; the insoluble part of the material was then filtered through quantitative filter paper; after ashing in a platinum crucible, the ash was evaporated with the mixture of hydrofluoric and perchloric acids. The residue solution, free of fluoride, was combined with the previously obtained filtrate. After evaporating the solution almost to dryness, the residue was dissolved in concentrated hydrochloric acid and the extraction of niobium could be carried out according to the Procedure. Niobium was determined by the developed method in certified geological material (apatite) CTA-AC-1. According to the certificate, average of the results obtained in different laboratories were in the range $(3.17-5.62) \times 10^{-3} \%$. The results are shown in Table 2 .

The certified steel samples were dissolved in the conventional manner using a mixture of sulfuric, phosphoric and nitric acids. The solution was diluted in
Table 3 Results of niobium determination in certified steel samples

\begin{tabular}{|c|c|c|c|c|}
\hline \multirow{2}{*}{ Sample/g } & \multicolumn{2}{|c|}{ Niobium $/ \mu \mathrm{g}(\%)$} & \multirow{2}{*}{$\begin{array}{c}\text { RSD, } \% \\
(n=7)\end{array}$} & \multirow{2}{*}{$\begin{array}{c}\text { Confidence } \\
\text { limits }^{\mathrm{a}}\end{array}$} \\
\hline & Added & Found & & \\
\hline \multicolumn{5}{|c|}{ (ASMW $4.10 / 1$ certified niobium content $0.34 \%$ ) } \\
\hline 0.075 & - & $\begin{array}{c}10.1 \\
(0.34)\end{array}$ & 0.8 & $(0.34 \pm 0.01)$ \\
\hline 0.075 & 6.0 & 16.0 & & \\
\hline \multicolumn{5}{|c|}{ (IMŹ 1.76 certified niobium content $0.069 \%$ ) } \\
\hline 0.070 & - & $\begin{array}{c}10.1 \\
(0.072)\end{array}$ & 2.6 & $(0.072 \pm 0.002)$ \\
\hline 0.070 & 6.0 & 15.8 & & \\
\hline \multicolumn{5}{|c|}{ (IMŹ 4.61 certified niobium content $0.017 \%$ ) } \\
\hline 0.060 & - & $\begin{array}{c}9.1 \\
(0.015)\end{array}$ & 3.8 & $(0.015 \pm 0.001)$ \\
\hline 0.060 & 6.0 & 15.6 & & \\
\hline
\end{tabular}

a. Probability level $=0.95$.

a volumetric flask with concentrated hydrochloric acid; an appropriate aliquot of the sample (depending on the niobium content) was then analyzed. The results are shown in Table 3.

The authors wish to thank Professor Jerzy Jurczyk of the Institute of Ferrous Metallurgy, Poland, for the gift of reference steel samples.

\section{References}

1 Z. Marczenko, "Separation and Spectrophotometric Determination of Elements", Ellis Horwood, Chichester, 1986.

2. M. A. J. Sanchez, A. Francisco, F. Jimenez and F. Garcia Montelongo, Talanta, 36, 831 (1989).

3. B. Welz, "Atomic Absorption Spectrometry", p. $308, \mathrm{VCH}$, Weinheim, 1985.

4. O. A. Vita, W. A. Levier and E. Litteral, Anal. Chim. Acta, 42, 87 (1968).

5. J. Aznarez, J. Galban, F. Palacios and J. C. Vidal, Analyst [London], 10, 193 (1985).

6. M. Jarosz, S. Oszwałdowski and Z. Marczenko, Chem. Anal. [Warsaw], 37, 335 (1992).

7. H. Yoshida and C. Yonezawa, J. Radioanal. Chem., 5, 201 (1970).

8. A. Sanz Medel and M. E. Diaz, Analyst [London], 106, 1268 (1981).

(Received July 9, 1992)

(Accepted November 11, 1992) 